\title{
Introduction to the Special Issue: Connectivity in Geomorphology
}

\author{
Ellen Wohl ${ }^{1, *}$, Francis J. Magilligan ${ }^{2}$, Sara L. Rathburn ${ }^{1}$
}

\begin{abstract}
With the increased recent attention on understanding the complex pathways and fluxes of material, energy, and organisms and the multidimensional coupling between various geomorphic process domains, the 47th Binghamton Geomorphology Symposium was organized around the theme of Connectivity in Geomorphology. Six key subthemes emerged: sediment connectivity, hydrologic connectivity, geochemical connectivity, riverine connectivity, landscape connectivity, and modeling of connectivity. Papers presented at the symposium and collected in this special issue elucidate the theoretical and conceptual underpinnings of connectivity but also provide field-based and analytical approaches to document the fundamental role of connectivity in geomorphic and ecological functioning. Among the consistent themes that emerged from the papers and from discussion during the symposium were (1) the interconnectedness of diverse forms of connectivity, (2) the appropriateness (or not) of conceptualizing connectivity as a gradient or continuum, and (3) the importance of an explicit recognition of disconnectivity as a mechanism to retain ecologically important materials and organisms within landscapes. Knowledge gaps identified in discussions during the symposium include: identifying questions that can be usefully addressed within a framework emphasizing connectivity; identifying feedbacks that enhance and limit connectivity; and quantification - of diverse aspects of
\end{abstract}


23 connectivity, of thresholds of connectivity, and of interactions among different types of

24 connectivity.

25 Keywords: connectivity; sediment; landscape; rivers; modeling

\section{Introduction}

Connectivity - the transfer of matter, energy, or organisms between two different

28 landscape compartments (Pringle, 2001, 2003; Jain and Tandon, 2010; Wainwright et al., 2011;

29 Fryirs, 2013) - has been an important conceptual framework within geomorphology for decades.

30 Its initial articulation focused perhaps more on sediment coupling between hillslopes and

31 channels (Harvey, 1991, 2002); but with the greater contemporary focus in geomorphology on

32 watershed-scale processes and geomorphology's associated linkage with cognate fields such as

33 ecology, hydrology, and geochemistry, connectivity has become an all-embracing term to

34 represent the multidimensional fluxes of energy and matter at all scales and through multiple

35 processes. With the protracted impacts of anthropogenic disturbance commonly associated with

36 dams and other infrastructure such as levees and retaining walls, connectivity has taken on

37 greater saliency through its counterpart - disconnectivity - which further serves to quantify the

38 magnitude of the cessation or attenuation of watershed, reach scale, and local connectivity (Ward

39 and Stanford, 1995; Magilligan et al., 2003; Kondolf et al., 2006; Fryirs, 2013; Wohl and

40 Beckman, 2014). Moreover, as river restoration has become an important scientific, social, and

41 policy initiative, a significant management thrust has reestablished connectivity through, for

42 example, dam removal, large wood additions, and levee relocation; yet fear/hesitation exists

43 within the geomorphic community that the science of river restoration may lag behind its

44 application (Wohl et al., 2015). 
In addition, with the recent initiation of the Critical Zone Observatories $(\mathrm{CZO})$ in the

46 U.S. (http://criticalzone.org/national/), there has been a greater recognition of, and focus on, the

47 important atmospheric-terrestrial-ecological linkages, especially the quantification of how rocks,

48 soil, water, air, and living organisms interact. The emergence of this research agenda has further

49 necessitated a greater need to document material fluxes across spatial and temporal scales and to

50 better establish the governing conditions that control the rate and pathways of these exchanges.

\section{2. Rationale for symposium on connectivity}

53 Although the concepts underlying connectivity are implicit in the earliest geomorphic

54 thinking, ecologists have largely been responsible for reintroducing and popularizing the concept

55 of connectivity during the past decade (cf. Pringle, 2001, 2003). However, the geomorphic

56 community is increasingly explicitly emphasizing connectivity as a conceptual framework to

57 understand fluxes, transfers, and transient and long-term storage of material and energy within

58 landscapes. Nevertheless, the contours and specific attributes of a geomorphic framing of

59 connectivity have been woefully lacking; hence the need for a symposium to better articulate a

60 geomorphic vision of connectivity.

61 Most geomorphic attention has focused on riverine connectivity, which conceptually can

62 be envisioned in a multidimensional space (Kondolf et al., 2006) that represents the exchange of

63 material longitudinally, laterally, and vertically within and across watersheds and stream

64 channels. Most recent geomorphic attention has focused on longitudinal connectivity, especially

65 with the NSF Margins initiative and its associated source-to-sink research rubric (Aalto et al.,

66 2008), although the exchange of sediment between channels and floodplains (lateral

67 connectivity) during overbank flows has long been a research theme in geomorphology (Knox, 
1972; Magilligan, 1985; Walling and Owens, 2003). Less attention has been paid to vertical

69 connectivity, but with the recognition of the ecological dimensions of hyporheic flows (Stanford

70 and Ward, 1988), there has been a sustained interest in quantifying the critical sediment and

71 geochemical exchanges between the channel bed and subsurface (Cui et al., 2008; Wooster et al.,

72 2008; Gartner et al., 2012; Covino, 2016; Stewardson et al., 2016).

73 In response to the increasing explicit recognition of the different dimensions and fluxes

74 that can be conceptualized within a framework of connectivity, the $47^{\text {th }}$ Binghamton

75 Geomorphology Symposium (BGS) was organized around six distinct subthemes of hydrologic

76 connectivity, sediment connectivity, geochemical connectivity, riverine connectivity, landscape

77 connectivity, and modeling of connectivity (Fig. 1). Participants in the symposium explored

78 issues of how to conceptualize and quantify diverse aspects of connectivity and also identified

79 gaps in geomorphic understanding and application of connectivity.

Why a BGS? The BGS is one of the most recognizable annual geoscience meetings

81 worldwide. For nearly 50 years, the symposium series has addressed a wide range of scientific

82 and socially relevant topics in geomorphology, engaging a multitude of international

83 geoscientists (Table 1). Paying close attention to the previous BGS's goal of producing

84 scientifically relevant topics, the $47^{\text {th }}$ BGS was organized around subthemes of connectivity in

85 geomorphology (Table 2).

Among the existing gaps in developing a connectivity framework are (i) determining

87 what research and management questions can be most effectively addressed within a conceptual

88 framework that emphasizes connectivity; (ii) quantifying the different facets of connectivity

89 (e.g., magnitude of fluxes, duration, frequency, timing, spatial extent) that occur within a natural

90 system such as a river; (iii) quantifying thresholds of connectivity that, if crossed, can 
91 significantly alter system function (e.g., reduced river longitudinal connectivity associated with

92 reduced peak flows and resulting loss of fish migration); (iv) quantifying how different facets of

93 connectivity interact; and (v) identifying feedbacks that enhance and limit connectivity. A simple

94 but pertinent example of how different facets of connectivity interact comes from canyon rivers

95 with dams. In these rivers, lateral sediment connectivity typically persists between uplands and

96 the river corridor; but longitudinal hydrologic connectivity is lost as peak flows are stored behind

97 the dam, causing an accumulation of sediment within the river corridor and associated changes in

98 river form and habitat.

99

100

\section{Outcomes of symposium and special issue}

The two-day BGS and resulting special issue reveal that connectivity offers an important

102 framework for understanding geomorphic processes at multiple scales. In particular, the papers

103 on sediment connectivity stressed the fundamental importance of landscape scale and watershed

104 structure in explaining the fate of sediment. Rice et al. (2016) examine the role of network

105 structure and the resulting distribution of tributary confluences to help explain the pattern of

106 channel aggradation. They test an automated method for predicting the likelihood of tributary-

107 driven aggradation in three large drainage networks and show that their model can correctly

108 identify $\sim 75 \%$ of significant tributary confluences and $97 \%$ of insignificant confluences.

109 Continuing on this theme of watershed structure, Gran and Czuba (2016) address the role of

110 network structure in maintaining, dispersing, or transforming sediment pulses in fluvial systems.

111 Their results indicate that the network structure, in terms of network geometry and the spatial

112 pattern of transport capacity, can control sediment connectivity, especially where significant

113 geologically controlled bottlenecks occur and should be considered when predicting sediment

114 pulse behavior at the watershed scale. Looking more at channel-hillslope coupling and the 
115 relative efficacy of the supply and delivery of coarse material to the channel, Sklar et al. (2016)

116 illustrate how the spatial variation in weathering regime can lead to bimodal size distributions

117 and downstream fining of channel sediment by downvalley fining of hillslope sediment supply

118 using two examples of hillslope control on river sediment size.

119 The papers on hydrologic connectivity also stress the importance of scale and structure in

120 understanding connectivity. Passalacqua (2016) explores network representations of deltas as

121 links and nodes and develops the Delta Connectome. The Connectome conceptualizes a delta as

122 a leaky network with continual exchanges of matter and energy between the network and the

123 surroundings. The leakiness, or connectivity, of the network can be quantified by measuring

124 selected fluxes and changes in delta form through time. Gooseff et al. (2016) use the relatively

125 simple structure and seasonal changes that occur in the McMurdo Dry Valleys of Antarctica to

126 characterize hydrologic connectivity within the valley bottoms. They find that even in this

127 relatively simple setting, the magnitude, spatial extent, and duration of hydrologic connectivity is

128 dynamic, with variations over multiple orders of magnitude. They propose simple hydrologic

129 metrics for characterizing this connectivity, with a focus on flow volume (including lack of flow)

130 and frequency. Macfarlane et al. (2016) explore changes in hydrologic connectivity associated

131 with beaver dams, which change not only surface stream flow but also surface-hyporheic

132 exchanges and evapotranspiration and water balance in valley bottoms. They present a capacity

133 model that can be used to predict the limits of riverscapes to support beaver dams and test the

134 model in watersheds of several states in the western United States, finding good agreement

135 between model predictions and actual dam locations. The model provides an example of how

136 existing databases can be used to predict alterations of diverse forms of hydrologic connectivity

137 within river networks as a result of a specific type of alteration - in this case, beaver dams. Each 
138 of the three papers examining hydrologic connectivity emphasizes the implications of this form

139 of connectivity for biogeochemistry and biotic communities.

140 Geochemical connectivity under eroding hills is the focus of the BGS contribution by

141 Brantley et al. (2016). Vertical movement of uplifted rock on geologic timescales is subjected to

142 weathering as lateral movement through erosion. On shorter timescales, water fluxes move

143 vertically downward then laterally either as interflow, when permeability contrasts occur in the

144 weathering zone, or as deep groundwater. Such fluid flows set up shallow and deep weathering

145 fronts where active biogeochemical reactions occur. The rate of rock advection upward relative

146 to downward-acting weathering reactions governs rates at which minerals dissolve and erosion

147 removes rock particles. In some environments, weathering approximates erosion, leading to

148 steady-state conditions. The paper by Hilton (2016) relates climatic influences on export of

149 particulate organic carbon from the terrestrial biosphere ( $\left.\mathrm{POC}_{\text {biosphere }}\right)$ to geochemical

150 measurements, flow and suspended sediment quantities, and catchment slope in a sample of

151 global forested watersheds. Results indicate that catchments with steep slopes may contribute

152 nearly half of the global $\mathrm{POC}_{\text {biosphere }}$ erosion flux and that a significant relationship exists

153 between annual runoff and annual $\mathrm{POC}_{\text {biosphere, }}$ supporting strong connectivity between forested

154 hillslopes and rivers. Furthermore, a model of climate influences on rates of runoff and hence

155 erosion and discharge of $\mathrm{POC}_{\text {bioshere }}$ indicates that small increases in annual runoff result in an

156 approximately four-fold increase in $\mathrm{POC}_{\text {biosphere }}$ discharge, underscoring the sensitivity of carbon

157 fluxes to predicted changes in runoff. A final paper on geochemical connectivity by Covino

158 (2016) documents how hydrological connections span numerous spatial dimensions and

159 spatiotemporal scales, creating a mosaic of nested processes. Understanding hydrologic flow

160 paths is essential to geochemical connectivity because water moves through heterogeneous 
161 subsurface environments that have the potential to increase or decrease nutrient and carbon

162 loading to the channel network. To advance our understanding of hydrologic connectivity and

163 how it influences carbon and nutrient dynamics, a concerted effort in field-based investigations

164 across broad spatial and temporal scales and modeling efforts that explicitly address process

165 heterogeneity and feedbacks is essential.

166 The papers addressing riverine connectivity examine the multidimensional physical and

167 social aspects of connectivity and the fundamental ecological and geomorphic importance of

168 disconnectivity. Although acknowledging the importance of considering and conceptualizing

169 connectivity, Grant et al. (2016) elucidate the critical role of disconnectivity and discontinuities

170 in watershed processes. As they assert, a discontinuous view provides an important spatial and

171 temporal framing as it incorporates nonuniform, nonprogressive, and nonequilibrium thinking

172 into understanding geomorphic processes and landscapes. Echoing Renwick (1992) and Phillips

173 (1992), they assert that not all landscapes tend toward a presumed equilibrium state and that,

174 depending on the spatial and temporal lens, it is the disruptions in the system that provide an

175 important element of geomorphic and ecological complexity. Cadol and Wine (2016) focus on

176 the directionality of connectivity and show that geomorphology can be a first-order control on

177 riparian ecohydrology by conditioning the magnitude and rate of geochemical and hydrologic

178 exchanges in semiarid settings. Using detailed field, climatic, and geospatial data, they quantify

179 the association between vegetation greenness (using EVI) and valley metrics (width, slope, and

180 concavity) and the interannual variability in flow and rainfall characteristics. Their detailed

181 statistical analysis reveals great statistical and ecological value in including geomorphic

182 parameters along with climatic and hydrologic information to quantify vegetation greenness.

183 The geomorphic parameters, especially valley curvature, may not just create statistical 
184 relationships but may indicate physical causal processes, such as increased soil moisture

185 availability on concave surfaces, which generates convergent subsurface flow paths. In an

186 attempt to characterize the role of anthropogenic, geologic, and geomorphic boundary conditions

187 on the rate and magnitude of longitudinal connectivity, Wohl et al. (2016) parameterize

188 connectivity along North St. Vrain Creek watershed in Colorado with the specific focus of

189 identifying the role of reach-scale channel gradient as a first-order control on geomorphic and

190 geochemical exchanges. Using readily available topographic, lithologic, climatic, infrastructural

191 (e.g., dams and roads), and vegetation data, they rank these landscape scale controls that, in

192 concert with reach-scale gradient, dictate the rate of geochemical and sedimentological fluxes

193 (and direction). They show that steep channel reaches engender the highest longitudinal

194 connectivity for all materials considered, whereas lower gradient reaches attenuate longitudinal

195 connectivity and generate longer residence time of water, sediment, and organic matter.

196 However, despite limiting longitudinal connectivity, these lower gradient reaches generate

197 greater lateral (channel-floodplain) and vertical (channel-hyporheic) connectivity.

198 Disconnectivity in the fluvial system can extend into the social engagement with rivers and

199 riverscapes. As geomorphologists we tend to focus on fluxes of sediment and nutrients, but as

200 Kondolf and Pinto (2016) remind us, connectivity can also refer to the communication and

201 movement of people, goods, ideas, and culture along and across river and may exhibit the same

202 dimensions of longitudinal, lateral, and vertical connectivity. Moreover, as they show in their

203 expansive international coverage, the social fabric of rivers has been significantly affected by

204 human alterations of the channel and the broader riparian zone, further suggesting that

205 reconnecting rivers geomorphically may have important social implications. 
To address landscape connectivity, Nicholl and Brierly (2016) investigate process

208 linkages related to sediment flux in two basins of the upper Yellow River using a GIS-based

209 connectivity index compared to satellite image interpretation and field mapping. They find that

210 landscape connectivity governs sediment availability, transport frequency, and sediment storage

211 sites in the basin. Although the two methods generally confirm patterns of landscape

212 connectivity, some areas of disconnectivity were misidentified, leading the authors to conclude

213 that within-basin variability in connectivity may be missed without field appraisals of the

214 landscape dynamics that control erosion and deposition. The paper by Lane et al. (2016)

215 examines the response of glaciated regions to climatic warming. Using nearly 40 years of

216 sediment flushing records from hydropower operations, the authors quantify coarse sediment

217 export from a basin undergoing rapid glacial recession in the Swiss Alps. These data, combined

218 with sediment transport capacities, DEM of differencing, and hydrologic routing, indicate that

219 increased sediment yields from glacial recession may be offset by increased resistance to

220 transport, challenging the hypothesis that an increase in paraglacial areas as glaciers retreat

221 increases sediment export through connectivity. Results suggest that negative feedbacks may

222 limit coarse sediment transport in upper portions of the basin. In the paper by May et al. (2016),

223 waterfalls are shown to create conditions of landscape disconnectivity. In streams within the

224 Oregon Coast Range, USA, bedrock knickpoints forming waterfalls isolate salmonid populations 225 compared to catchments without knickpoints. The authors conclude that knickpoints control base

226 level and hence channel incision such that lower channel slopes, wider valley bottoms, and

227 increased resilience to landslide disturbances support greater habitat quantity and quality. A

228 conceptual connectivity framework is presented by Poeppl et al. (2016) to describe geomorphic

229 change in human-impacted fluvial systems. The authors contend that no systematic data are 
230 available on how different types of human activity affect connectivity relationships. Application

231 of the framework brings increased understanding of connectivity and complexity in fluvial

232 geomorphology, especially in coupled human-geomorphic systems.

233 The final subtheme of the BGS focused on modeling connectivity, although all of the

234 papers included some discussion of qualitative or quantitative modeling. Houssais and Jerolmack

235 (2016) note the tendency to differentiate landscapes into process domains and develop sediment

236 transport laws for each domain. Noting the consistency of basic components of grain

237 entrainment, they return to a perspective originally advocated by Bagnold $(1954,1956)$ and

238 conceptualize the longitudinal profile of a hillslope-river-shelf system as equating to a gradient

239 of decreasing dominance by granular friction and increasing dominance by fluid drag on

240 transport capacity. One outcome of this is recognition of the importance of creep by sediment

241 particles in both hillslope and river systems, which implies the possibility of unifying sediment

242 transport across diverse environments. Coulthard and Van de Wiel (2016) use the CAESAR

243 landscape evolution model to explore connectivity in the River Swale basin of England. They

244 focus on how changes in vegetation cover alter erosion, deposition, and sediment yield and how

245 sediment dynamics reflect basin-scale connectivity expressed through linkages from upstream to

246 downstream areas, but also from downstream to upstream areas.

\section{4. Toward a synthesis of connectivity}

Among the points that emerged consistently from the very different treatments of

249 connectivity in the papers included in the special issue are (i) the arbitrariness of commonly

250 employed scientific divisions of connectivity, (ii) leakiness, and (iii) disconnectivity. Although

251 many papers focus on a distinct form of connectivity, such as the movement of sediment or

252 water, the papers in this special issue clearly indicate that such distinctions are arbitrary and 
253 limited, as is the organization of the papers into subthemes. Most of the papers overlap in the

254 forms of connectivity that they address because the fluxes of diverse materials and organisms

255 throughout the critical zone are inextricably intermingled. A second point that emerged

256 repeatedly in the papers and in discussions during the symposium is that connectivity is not most

257 appropriately conceptualized as an on-off switch, but rather a dimmer switch because fluxes

258 occur along a continuum across space and through time. Distinguishing channelized flow within

259 a river corridor may be convenient, for example, but an extensive literature clearly documents

260 that river flow is leaky, with hyporheic exchanges, groundwater exchanges, atmospheric inputs

261 and losses, and channel-floodplain exchanges. Similarly, papers such as Passalacqua (2016)

262 explicitly recognize the leakiness of a delta network. Finally, connectivity implies the corollary

263 of disconnectivity. Disconnectivity is an equally important concept but is less emphasized in

264 many contexts than connectivity (although important exceptions exist: e.g., Burchsted et al.,

265 2010, 2014; Fryirs, 2013; Grant et al., 2016). Disconnectivity becomes especially important in

266 understanding how ecosystems retain matter, energy, and organisms over timescales relevant to

267 living organisms (e.g., watersheds retaining excess sediment and nutrients resulting from land

268 use, or nearshore environments retaining nutrients from fluvial inputs). Future work will build

269 upon the papers in this special issue to synthesize geomorphic approaches to connectivity and fill

270 in the knowledge gaps identified here.

\section{Acknowledgements}

272 The $47^{\text {th }}$ Binghamton Geomorphology Symposium was supported by funding from the National

273 Science Foundation (EAR1523631), Dartmouth College, Colorado State University, MWH

274 Americas, and Otak.

275

276 


\section{References Cited}

Aalto, R., Lauer, J.W., Dietrich, W.E., 2008. Spatial and temporal dynamics of sediment accumulation and exchange along Strickland River floodplains (Papua New Guinea) over decadal-to-centennial timescales. Journal of Geophysical Research-Earth Surface 113. doi:10.1029/2006jf000627

Bagnold, R.A., 1954. Experiments on a gravity-free dispersion of large solid spheres in a Newtonian fluid under shear. Proc. R. Soc. A Math. Phys. Eng. Sci. 225 (1160), 49-63.

Bagnold, R.A., 1956. The flow of cohesionless grains in fluids. Philos. Trans. R. Soc. Lond. A 249 (964), 235-297.

Brantley, S.L., Lebedeva, M.I., Balashov, V.N., Singha, K., Sullivan, P.L., Stinchcomb, G., 2016. Toward a conceptual model relating chemical reaction fronts to water flow paths in hills. Geomorphology, http://dx.doi.org/10.1016/j.geomorph.2016.09.027

Burchsted, D., Daniels, M., Thorson, R., Vokoun, J., 2010. The river disctoninuum: applying beaver modifications to baseline conditions for restoration of forested headwaters. BioScience 60, 908-922.

Burchsted, D., Daniels, M., Wohl, E.E., 2014. Introduction to the special issue on discontinuity of fluvial systems. Geomorphology 205, 1-4.

Cadol, D., and Wine, M.L., 2016. Geomorphology as a first-order control on the connectivity of riparian ecohydrology. Geomorphology. http://dx.doi.org/10.1016/j.geomorph.2016.06.022

Covino, T., 2016. Hydrologic connectivity as a framework for understanding biogeochemical flux through watersheds and along fluvial networks. Geomorphology. doi:10.1016/j.geomorph.2016.09.030

Cui, Y., Wooster, J.K., Baker, P.F., Dusterhoff, S.R., Sklar, L.S., Dietrich, W.E., 2008. Theory of fine sediment infiltration into immobile gravel bed. Journal of Hydraulic EngineeringAsce 134, 1421-1429. doi:10.1061/(asce)0733-9429(2008)134:10(1421)

Fryirs, K., 2013. (Dis) Connectivity in catchment sediment cascades: a fresh look at the sediment delivery problem. Earth Surface Processes and Landforms 38, 30-46.

Gartner, J.D., Renshaw, C.E., Dade, W.B., Magilligan, F.J., 2012. Time and depth scales of fine sediment delivery into gravel stream beds: Constraints from fallout radionuclides on fine sediment residence time and delivery. Geomorphology 151, 39-49. doi:10.1016/j.geomorph.2012.01.008

Gooseff, M.N., Wlostowski, A., McKnight, D.M., Jaros, C., 2016. Hydrologic connectivity and implications for ecosystem processes -- lessons from naked watersheds. Geomorphology, http://dx.doi.org/10.1016/j.geomorph.2016.04.024

Gran, K.B., Czuba, J.A., 2016. Sediment pulse evolution and the role of network structure. Geomorphology. doi:10.1016/j.geomorph.2015.12.015

Grant, G.E., O'Connor, J.E., and Safran, E., 2016. Excursions in fluvial (dis)continuity. Geomorphology. http://dx.doi.org/10.1016/j.geomorph.2016.08.033

Harvey, A., 1991. The influence of sediment supply on the channel morphology of upland streams: Howgill Fells, Northwest England. Earth Surface Processes and Landforms 16, 675-684. 
Harvey, A.M., 2002. Effective timescales of coupling within fluvial systems. Geomorphology 44, 175-201.

Hilton, R.G., 2016. Climate regulates the erosional carbon export from the terrestrial biosphere. Geomorphology. doi:10.1016/j.geomorph.2016.03.028.

Houssais, M., Jerolmack. D.J., 2016. Toward a unifying constitutive relation for sediment transport across environments. Geomorphology, http://dx.doi.org/10.1016/j.geomorph.2016.03.026

Jain, V., Tandon, S.K., 2010. Conceptual assessment of (dis) connectivity and its application to the Ganga River dispersal system. Geomorphology 118, 349-358.

Knox, J.C., 1972. Valley alluviation in southwestern Wisconsin. Annals of the Association of American Geographers 62, 401-410.

Kondolf, G.M., Boulton, A.J., O’Daniel, S., Poole, G.C., Rachel, F.J., Stanley, E.H., Wohl, E., Bang, A., Carlstrom, J., Cristoni, C., Huber, H., Koljonen, S., Louhi, P., Nakamura, K., 2006. Process-based ecological river restoration: Visualizing three-dimensional connectivity and dynamic vectors to recover lost linkages. Ecology and Society 11.

Kondolf, G.M., and Pinto, P.J., 2016. The social connectivity of urban rivers. Geomorphology. http://dx.doi.org/10.1016/j.geomorph.2016.09.028

Lane, S.N., Bakker, M., Gabbud, C., Micheletti, N., and Saugy, J.N., 2016. Sediment export, transient landscape response and catchment-scale connectivity following rapid climate warming and Alpine glacier recession, Geomorphology. doi:10.1016/j.geomorph.2016.02.015.

Macfarlane, W.W., Wheaton, J.M., Bouwes, N., Jensen, M.L., Gilbert, J.T., Hough-Snee, N., Shivik, J.A., 2016. Modeling the capacity of riverscapes to support beaver dams. Geomorphology, http://dx.doi.org/10.1016/j.geomorph.2015.11.019

Magilligan, F.J., 1985. Historical floodplain sedimentation In the Galena River Basin, Wisconsin and Illinois. Ann. Assoc. Am. Geogr. 75, 583-594.

Magilligan, F.J., Nislow, K.H., Graber, B.E., 2003. Scale-independent assessment of discharge reduction and riparian disconnectivity following flow regulation by dams. Geology 31, $569-572$.

May, C., Roering, J., Snow, K., Griswold, K., Gresswell, R., 2016. The waterfall paradox: How knickpoints disconnect hillslope and channel processes, isolating salmonid populations in ideal habitats. Geomorphology. doi:10.1016/j.geomorph.2016.03.029.

Nicoll, T., and Brierley, G., 2016. Within-catchment variability in landscape connectivity measures in the Garang catchment, upper Yellow River. doi:10.1016/j.geomorph.2016.03.014.

Passalacqua, P., 2016. The Delta Connectome: a network-based framework for studying connectivity in river deltas. Geomorphology, http://dx.doi.org/10.1016/j.geomorph.2016.04.001

Poeppl, R.E., Keesstra, S.D., Maroulis, J., 2016. A conceptual connectivity framework for understanding geomorphic change in human-impacted fluvial systems. doi:10.1016/j.geomorph.2016.07.033.

Pringle, C.M., 2001. Hydrologic connectivity and the management of biological reserves: a global perspective. Ecological Applications 11, 981-998.

Pringle, C., 2003. What is hydrologic connectivity and why is it ecologically important? Hydrological Processes 17, 2685-2689. 
Rice, S.P., 2016. Tributary connectivity, confluence aggradation and network biodiversity. Geomorphology. doi:10.1016/j.geomorph.2016.03.027

Sklar, L.S., Riebe, C.S., Marshall, J.A., Genetti, J., Leclere, S., Lukens, C.L., Merces, V., 2016. The problem of predicting the size distribution of sediment supplied by hillslopes to rivers. Geomorphology. doi:10.1016/j.geomorph.2016.05.005

Stanford, J.A., Ward, J.V., 1988. The hyporheic habitat of river ecosystems. Nature 335, 64-66. Stewardson, M., Datry, T., Lamouroux, N., Pella, H., Thommeret, N., Valette, L., Grant, S., 2016. Variation in reach-scale hydraulic conductivity of streambeds. Geomorphology 259, 70-80.

Wainwright, J., Turnbull, L., Ibrahim, T.G., Lexartza-Artza, I., Thornton, S.F., Brazier, R.E., 2011. Linking environmental régimes, space and time: interpretations of structural and functional connectivity. Geomorphology 126, 387-404.

Walling, D., Owens, P., 2003. The role of overbank floodplain sedimentation in catchment contaminant budgets. Hydrobiologia 494, 83-91.

Ward, J.V., Stanford, J.A., 1995. The serial discontinuity concept - extending the model to floodplain rivers. Regul. Rivers-Res. Manage. 10, 159-168.

Wohl, E., Beckman, N.D., 2014. Leaky rivers: implications of the loss of longitudinal fluvial disconnectivity in headwater streams. Geomorphology 205, 27-35.

Wohl, E., Lane, S.N., Wilcox, A.C., 2015. The science and practice of river restoration. Water Resources Research 51, 5974-5997.

Wohl, E., Rathburn, S., Chignell, S., Garrett, K., Laurel, D., Livers, B., Patton, A., Records, R., 393 
Table 1

List of past Binghamton Geomorphology Symposia

Title

1. Environmental Geomorphology (1970)

2. Quantitative Geomorphology (1971)

3. Coastal Geomorphology (1972)

4. Fluvial Geomorphology (1973)

5. Glacial Geomorphology (1974)

6. Theories of Landform Development (1975)

7. Geomorphology and Engineering (1976)

8. Geomorphology in Arid Regions (1977)

9. Thresholds in Geomorphology (1978)

10. Adjustments of the Fluvial System (1979)

11. Applied Geomorphology (1980)

12. Space and Time in Geomorphology (1981)

13. Groundwater as a Geomorphic Agent (1982)

14. Models in Geomorphology (1983)

15. Tectonic Geomorphology (1984)

16. Hillslope Processes (1985)

17. Aeolian Geomorphology (1986)

18. Catastrophic Flooding (1987)

19. History of Geomorphology (1988)

20. Appalachian Geomorphology (1989)

21. Soils and Landscape Evolution (1990)

22. Periglacial Geomorphology (1991)

23. Geomorphic Systems (1992)

24. Geomorphology: The Research Frontier and Beyond (1993)

25. Geomorphology and Natural Hazards (1994)

26. Biogeomorphology, Terrestrial and Freshwater Systems (1995)

27. The Scientific Nature of Geomorphology (1996)

28. Engineering Geomorphology (1997)

29. Coastal Geomorphology (1998)

30. Geomorphology in the Public Eye: Policy Issues and Education (1999)

31. Integration of Computer Modeling and Field Work in Geomorphology (2000)

32. Mountain Geomorphology (2001)

33. Dams and Geomorphology (2002)

34. Ice Sheet Geomorphology (2003)

35. Weathering and Landscape Evolution (2004)

36. Geomorphology and Ecosystems (2005)

37. The Human Role in Changing Fluvial Systems (2006)

\section{Editor(s)}

D.R. Coates

M. Morisawa

D.R. Coates

M. Morisawa

D.R. Coates

W.N. Melhorn and R.C. Flemal

D.R. Coates

D.O. Doehring

D.R. Coates and J.D. Vitek

D.D. Rhodes and E.J. Williams

R.G. Craig and J.L. Craft

C.E. Thorn

R.G. LeFleur

M.J. Woldenberg

M. Morisawa and J.T. Hack

A.D. Abrahams

W.G. Nickling

L. Mayer and D. Nash

K.J. Tinkler

T.W. Gardner and W.D. Sevon

P.L.K. Knuepfer and L.D. McFadden

J. Dixon and A. Abrahams

J.D. Phillips and W.H. Renwick

J.D. Vitek and J.R. Giardino

M. Morisawa

C.R. Hupp, W.R. Osterkamp, A.D. Howard

B.L. Rhoads and C.E. Thorn

J.R. Giardino, R.A. Marston, M. Morisawa

P.A. Gares and D.J. Sherman

P.L.K. Knuepfer and J.F. Petersen

J.F. Shroder, Jr. and M.P. Bishop

D.R. Butler, S.J. Walsh, G.P. Malanson

P. Beyer

P.L.K. Knuepfer, J. Fleisher, D.R. Butler

A. Turkington, J. Phillips, S. Campbell

M. Doyle, M. Thoms, C. Renschler

L.A. James and W.A. Marcus
ISBN

Oct. $1970^{\mathrm{a}}$

Oct. $1971^{\mathrm{a}}$

$0-045-51038-5$

$0-045-51046-6$

$0-045-51045-8$

$0-686-10458-7$

$0-045-51040-7$

$0-045-51041-5$

$0-045-51033-4$

$0-840-32108-2$

$0-045-51050-4$

$0-045-51056-3$

0-045-51069-5

$0-045-51075-\mathrm{X}$

0-045-51098-9

0-045-51102-0

0-045-51133-0

$0-045-51142-\mathrm{X}$

0-045-51138-1

0-444-88326-6

$0-444-88692-3$

0-471-93342-2

0-444-89809-3

0-444-89971-5

0-444-82012-4

0-444-81867-7

0-471-96811-0

0-444-50301-3

Nov. $2002^{\mathrm{b}}$

Oct. $2002^{\mathrm{b}}$

0-444-51532-1

0-444-51531-3

0-444-52231-X

April 2006 ${ }^{\mathrm{b}}$

0-444-52031-7

Sept. $2007^{\mathrm{c}}$

Sept. $2006^{\circ}$ 
38. Complexity in Geomorphology (2007)

39. Fluvial Deposits and Environmental History (2008)

40. Geomorphology and Vegetation: Interactions, Dependencies, and Feedback Loops (2009)

41. Geospatial Technologies and Geomorphological Mapping (2010)

42. Zoogeomorphology and Ecosystem Engineering (2011)

43. The Field Tradition in Geomorphology (2012)

44. Coastal Geomorphology \& Restoration (2013)

45. Planetary Geomorphology (2014)

46. Experimental Geomorphology (2015)

47. Connectivity in Geomorphology (2016)
A.B. Murray and M.A. Fonstad Nov. $2007^{\mathrm{c}}$

P. Hudson, K. Butzer, T. Beach Sept. $2008^{\mathrm{c}}$

W.C. Hession, T. Wynn, L. Resler, J. Curran

April 2010

L.A. James, M.P. Bishop, S.J. Walsh Jan. $2012^{\mathrm{c}}$

July $2012^{\mathrm{c}}$

Oct. $2013^{\mathrm{c}}$

Oct. $2013^{\mathrm{c}}$

July $2015^{\text {a }}$

Sept. $2015^{\mathrm{a}}$

\section{Notes}

${ }^{a}$ softcover copy published w/o ISBN

${ }^{\mathrm{b}}$ no hardbound volume published; published in Geomorphology (date listed)

${ }^{\mathrm{c}}$ hardbound copy published w/o ISBN 
Table 2

Connectivity themes addressed by presentations during the $47^{\text {th }}$ Binghamton Geomorphology Symposium

\begin{tabular}{ll}
\hline Connectivity theme & Topics (authors) \\
\hline Sediment & $\begin{array}{l}\text { Fluxes and storage of particulate mineral matter in any geomorphic environment - hillslope, glacial, eolian, } \\
\text { coastal, or fluvial (Rice et al., 2016; Gran and Czuba, 2016; Sklar et al., 2016) }\end{array}$
\end{tabular}

Hydrologic Fluxes and storage of water between the atmosphere and surface and subsurface geomorphic components (Passalacqua, 2016; Gooseff et al., 2016; Macfarlane et al., 2016)

Geochemical

Fluxes and storage of dissolved or particulate individual elements or compounds, such as nitrogen and organic carbon, throughout the critical zone (Brantley et al., 2016; Hilton, 2016; Covino, 2016)

Riverine

Fluxes and storage of water, solutes, sediment, particulate organic matter, and organisms within channel and river corridors and throughout river networks (Grant et al., 2016; Cadol and Wine, 2016; Wohl et al., 2016; Kondolf and Pinto, 2016)

Landscape

Fluxes and storage of diverse forms of matter at the landscape scale (Nicholl and Brierly, 2016; Lane et al., 2016; May et al., 2016; Poeppl et al., 2016)

Modeling

Quantification of diverse forms of connectivity via physical experiments and numerical simulations (Houssais and Jerolmack, 2016; Coulthard and Van de Wiel, 2016) 
Fig. 1

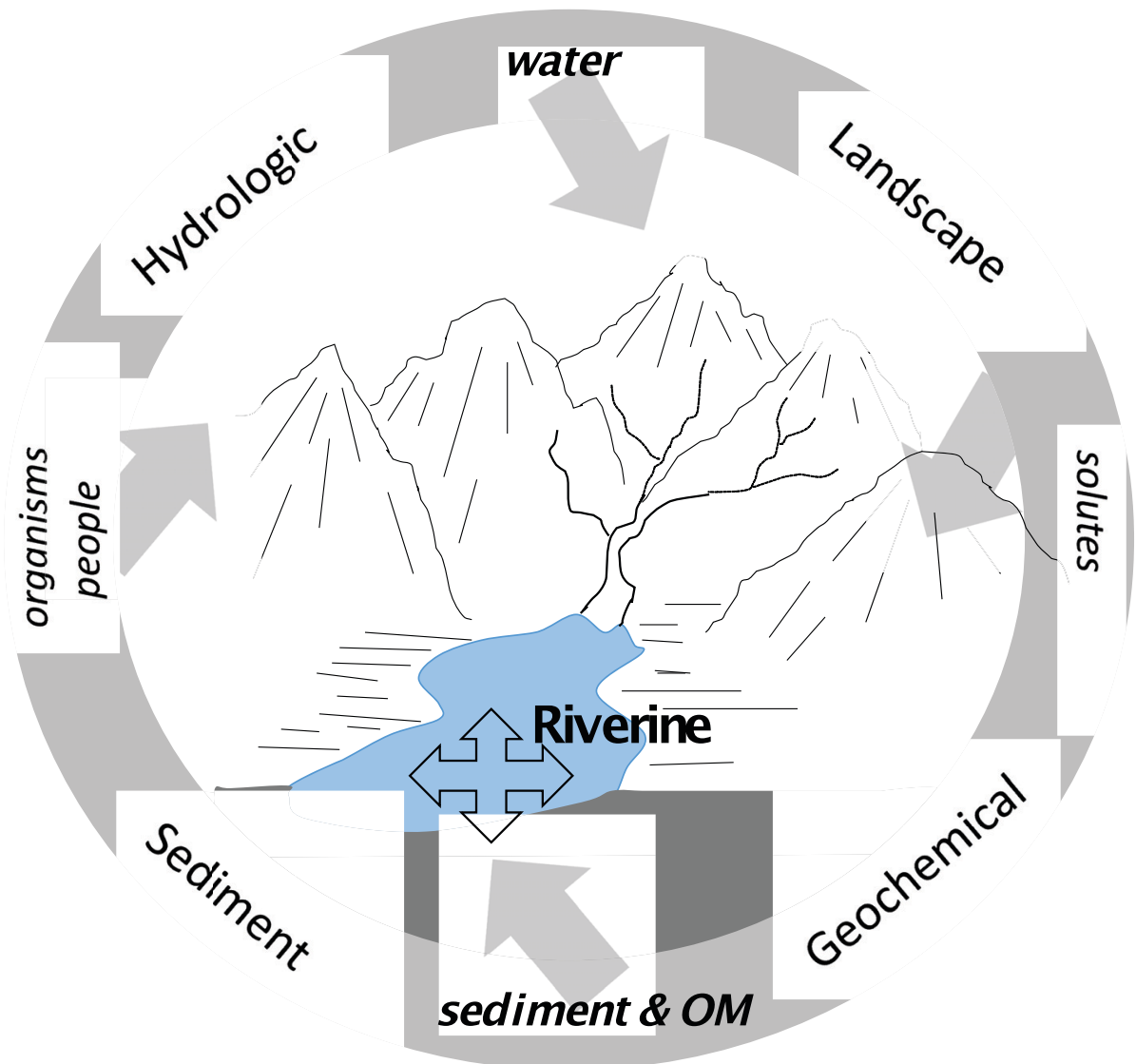

A schematic representation of the diverse forms of connectivity and the fundamental interconnectedness of the critical zone. In this illustration, the italicized words represent materials and organisms in flux and the words in regular font represent forms of connectivity on which the geomorphic community tends to focus. Modeling of connectivity, whether conceptual or quantitative, is inherent in all expressions of connectivity. This illustration also reflects the fact that - although disconnectivity can be critically important to ecosystem functioning and to geomorphic process and form - matter, energy, and organisms within the critical zone are ultimately connected at the largest time and space scales. 